\title{
Excitation functions for the formation of some short-lived products in proton-induced reactions on silver
}

\author{
By M. S. Uddin ${ }^{1, *}$, M. Baba², M. Hagiwara ${ }^{2}$, S. K. A. Latif ${ }^{1}$ and S. M. Qaim ${ }^{3}$ \\ ${ }^{1}$ Institute of Nuclear Science and Technology, Atomic Energy Research Establishment, Savar, GPO Box No. 3787, Dhaka 1000, Bangladesh \\ ${ }^{2}$ Cyclotron and Radioisotope Center, Tohoku University, Aramaki, Aobaku, 980-8578 Sendai, Japan \\ ${ }^{3}$ Institut für Nuklearchemie, Forschungszentrum Jülich GmbH, 52425 Jülich, Germany
}

(Received March 13, 2007; accepted in final form September 12, 2007)

Nuclear reaction / Excitation function /

${ }^{103} \mathrm{Ag}$ as parent of ${ }^{103} \mathrm{Pd}$

Summary. Excitation functions of the ${ }^{\text {nat }} \mathrm{Ag}(p, x n)^{104,105} \mathrm{Cd}$ and ${ }^{\text {nat }} \mathrm{Ag}(p, p x n)^{103,104 \mathrm{~m}, \mathrm{~g}, 104 \mathrm{~g}} \mathrm{Ag}$ reactions were measured for the first time over the proton energy range of 32 to about $60 \mathrm{MeV}$. The data were compared with the results of precompound-hybrid model calculations, whereby only partial agreement was obtained. The contribution of the ${ }^{103} \mathrm{Ag}$ precursor decay to the total formation of the therapeutic radionuclide ${ }^{103} \mathrm{Pd}$ in proton activation of silver was estimated: it amounted to about $70 \%$. The various possible routes for the production of ${ }^{103} \mathrm{Pd}$ were also considered: the ${ }^{\text {nat }} \mathrm{Ag}(p, x){ }^{103} \mathrm{Pd}$ and ${ }^{103} \mathrm{Rh}(p, n){ }^{103} \mathrm{Pd}$ processes were found to be most interesting. Despite its somewhat lower yield, the latter process is preferred because it can be applied at a low-energy cyclotron.

\section{Introduction}

Nuclear reaction cross section data for the production of all radionuclides (both with short and long half-lives) are needed in macroscopic estimation of dose/activity relevant to the analysis of radiation environment around an accelerator as well as for the optimization of production conditions of medical radioisotopes. In particular for the latter, full excitation function of the nuclear process is needed to be able to deduce the product yield with a reasonable accuracy.

A number of radionuclides are produced directly whereas a few others are produced through the decay of the parent nuclides. In some cases a short-lived radionuclide has great importance in creating an intermediate link and providing an additional channel for the long-lived nuclide accumulation. One such case is furnished by ${ }^{103} \mathrm{Ag}\left(T_{1 / 2}=\right.$ $1.1 \mathrm{~h})$. This radionuclide produced via the ${ }^{\text {nat }} \mathrm{Ag}(p, x)$ process completely decays to ${ }^{103} \mathrm{Pd}\left(T_{1 / 2}=17.0 \mathrm{~d}\right)$, a very important therapeutic radionuclide. For the proper estimation of the ${ }^{103} \mathrm{Pd}$ production via proton activation of silver, accurate data for the formation of ${ }^{103} \mathrm{Ag}$ are needed.

\footnotetext{
*Author for correspondence (E-mail: shuza88@yahoo.co.in).
}

Fassbender et al. [1] reported data for the formation of long-lived products of the $\mathrm{Ag}+p$ reaction, especially ${ }^{103} \mathrm{Pd}$, but the data for short-lived products are not available in the literature. Hermanne et al. [2] studied the formation of ${ }^{103} \mathrm{Ag}$ via proton and deuteron induced reactions on ${ }^{\text {nat }} \mathrm{Pd}$. Due to the relatively low abundances of the palladium target nuclei involved $\left({ }^{102} \mathrm{Pd}: 1.02 \%,{ }^{104} \mathrm{Pd}: 11.14 \%,{ }^{105} \mathrm{Pd}: 22.33 \%\right.$, ${ }^{106} \mathrm{Pd}: 27.33 \%$ ), the yield of ${ }^{103} \mathrm{Ag}$ is low. Thus the use of a nat $\mathrm{Ag}$ target appeared to be more interesting to us. The long-lived products were investigated earlier and the cross section data have been reported [3]. The excitation functions for the formation of short-lived radionuclides were also measured as part of a comprehensive study of the proton induced activation of silver and this work describes those studies in some detail. The decay data of the investigated products, namely ${ }^{104} \mathrm{Cd},{ }^{105} \mathrm{Cd},{ }^{103} \mathrm{Ag}$ and ${ }^{104} \mathrm{Ag}$ are given in Table 1 (taken from NUDAT database [4]).

\section{Experimental technique}

The excitation functions were measured by the stackedfoil activation technique. The experimental setup and the methods of data analysis were similar to those described elsewhere [5]. We give here only some salient features of this study.

Several groups of silver (50 $\mu \mathrm{m}$ thick), copper $(100 \mu \mathrm{m}$ thick) and aluminum (500 $\mu \mathrm{m}$ thick) foils of natural isotopic composition were assembled in a stack. The stack with several identical groups was placed in an aluminum holder (12 $\mathrm{mm}$ in diameter), equipped with a long collimator for irradiation. The foils were pressed with several circular rings in front of the stack within the holder to avoid inclination along the beam. Copper and aluminum foils were inserted into the stack as monitors and beam energy degraders, and to check the beam parameters. The stacked foils were irradiated with collimated protons at beam currents of $100 \mathrm{nA}$ for 10 min using the $k=110 \mathrm{MeV}$ AVF Cyclotron at the Cyclotron and Radioisotope Center (CYRIC) of Tohoku University, in Sendai, Japan. The primary proton energy was $70 \mathrm{MeV}$ and care was taken in the determination of the energy degradation along the foils and the bombarding beam intensity. 
Table 1. Investigated reactions, Q-values and reaction products with decay data.

\begin{tabular}{|c|c|c|c|c|c|}
\hline Nuclide & $\begin{array}{l}\text { Contributing } \\
\text { reaction }\end{array}$ & $\begin{array}{l}\text { Q-value } \\
(\mathrm{MeV})\end{array}$ & Half-life & $\begin{array}{c}E \gamma \\
(\mathrm{keV})\end{array}$ & $\begin{array}{l}I \gamma \\
(\%)\end{array}$ \\
\hline \multirow[t]{2}{*}{${ }^{105} \mathrm{Cd}$} & ${ }^{107} \mathrm{Ag}(p, 3 n)$ & -21.59 & \multirow[t]{2}{*}{$55.5 \mathrm{~min}$} & 346.9 & 4.2 \\
\hline & ${ }^{109} \mathrm{Ag}(p, 5 n)$ & -37.45 & & 961.8 & 4.7 \\
\hline${ }^{104} \mathrm{Cd}$ & $\begin{array}{l}{ }^{107} \mathrm{Ag}(p, 4 n) \\
{ }^{109} \mathrm{Ag}(n)\end{array}$ & $\begin{array}{l}-29.42 \\
-45.88\end{array}$ & \multirow[t]{2}{*}{$57.7 \mathrm{~min}$} & \multirow[t]{2}{*}{709.3} & \multirow[t]{2}{*}{19.5} \\
\hline \multirow{4}{*}{${ }^{104} \mathrm{Ag}$} & $\begin{array}{l}{ }^{107} \mathrm{Ag}(p, 6 n) \\
{ }^{107}(p, p 3 n)\end{array}$ & $\begin{array}{l}-45.88 \\
-27.50\end{array}$ & & & \\
\hline & $\begin{array}{l}{ }^{107} \mathrm{Ag}(p, 4 n)^{104} \mathrm{Cd} \\
\left({ }^{104} \mathrm{Cd} \rightarrow{ }^{104} \mathrm{Ag}\right)\end{array}$ & -29.42 & \multirow{3}{*}{$1.15 \mathrm{~h}$} & \multirow[t]{3}{*}{941.6} & \multirow[t]{3}{*}{25.0} \\
\hline & ${ }^{109} \mathrm{Ag}(p, p 5 n)$ & -42.90 & & & \\
\hline & $\begin{array}{l}\left.{ }^{109} \mathrm{Ag}(p, 6 n)\right)^{104} \mathrm{Cd} \\
\left.{ }^{104} \mathrm{Cd} \rightarrow{ }^{104} \mathrm{Ag}\right)\end{array}$ & -45.88 & & & \\
\hline \multirow[t]{5}{*}{${ }^{103} \mathrm{Ag}$} & ${ }^{107} \mathrm{Ag}(p, p 4 n)$ & -35.90 & \multirow[t]{5}{*}{$1.1 \mathrm{~h}$} & 118 & 31.2 \\
\hline & ${ }^{107} \mathrm{Ag}(p, 5 n)^{103} \mathrm{Cd}^{a}$ & -40.82 & & 148 & \multirow[t]{4}{*}{28.3} \\
\hline & ${ }^{107} \mathrm{Ag}(p, t 2 n)$ & -27.42 & & & \\
\hline & ${ }^{107} \mathrm{Ag}(p, d 3 n)$ & -33.67 & & & \\
\hline & ${ }^{109} \mathrm{Ag}(p, p 6 n)$ & -43.96 & & & \\
\hline
\end{tabular}

a: ${ }^{103} \mathrm{Cd}$ decays by $\left(\mathrm{EC}+\beta^{+}\right)$to ${ }^{103} \mathrm{Ag}$.

\section{Data analysis}

A HPGe $\gamma$-ray detector (CANBERRA, EURISYS MEASURES, EGPC50-195-R) was used to measure the radioactivity of the residual nuclei in the activated foils without chemical separation. The measurement of activities of the short-lived radionuclides was started about $10 \mathrm{~min}$ after the end of irradiation. Each sample was recounted 2-3 times to avoid disturbance by overlapping $\gamma$-rays from undesired sources and in order to accurately evaluate cross sections for cumulative formation of the corresponding longer-lived daughter radionuclide. To minimize the relative errors of calibration, several gamma rays were considered for determining the activity of a given radionuclide, wherever it was possible. The detector to source distance was maintained long enough to keep the dead time below 5\% and to assure point - like source geometry and minimum pile-up losses.

The proton beam intensity was determined via the monitor reactions ${ }^{27} \mathrm{Al}(p, x)^{24} \mathrm{Na}$ and ${ }^{\text {nat }} \mathrm{Cu}(p, x)^{62,63} \mathrm{Zn}$ [6], which were induced in the front radioactive monitor foils of the stack, considering that the monitor foils were irradiated simultaneously and measured with the same detector and in a comparable geometry as the targets. To increase the reliability, we considered the differences between the individual flux values of the different monitor reactions. The use of multiple monitor reactions decreases the possibility of introducing unknown systematic errors in the activity determination. To avoid any mistake in determination of the effective bombarding energy of the target foils in the stack, the well-known excitation function of the monitor reaction, ${ }^{\text {nat }} \mathrm{Cu}(p, x)^{62} \mathrm{Zn}$ was remeasured and compared with the recommended values over the investigated energy region. The energy loss in the sample foils as well as in the degraders was calculated by the computer program SRIM-2003 [7]. The results on the monitor reaction were found to be within $5 \%$ in agreement with the recommendation both in magnitude and energy scale. This fact adds confidence to the new cross section results in this work and to the energy degradation calculation using the program SRIM-2003. The measured thickness of the foil plays an important role in obtaining consistency of energy scale with the recommended values.
From the decay rates of the radioactive products and the measured beam current, the cross sections were deduced by using the usual activation formula.

It was observed that two or more radionuclides emitted gamma rays having very close energies, which could not be resolved by the HPGe-detector and the software used. We separated contributions from different radionuclides to the peak area using other independent gamma rays. The data were corrected for the sum-coincidence effect caused by the coincidental detection of two or more gamma rays in cascade by using the SUMECC code [8].

The following uncertainties were considered in order to derive the total uncertainty in each cross section: statistical uncertainty of $\gamma$-ray counting $(<11 \%)$, uncertainty in the flux via monitor reaction $(\sim 7 \%)$, uncertainty due to the gamma-ray intensity $(\sim 2 \%)$ and the uncertainty in efficiency calibration of the gamma-ray detector $(\sim 6 \%)$. The overall uncertainty in the cross section is around $15 \%$.

\section{Results and discussion}

The cross sections for the formation of several radionuclides in the interactions of protons with silver measured in this work are presented in Table 2. They are all elemental cross sections and refer to ${ }^{\text {nat }} \mathrm{Ag}$ as the target material. The total uncertainties are also given. All the data have been measured for the first time. We discuss the various reactions below.

\subsection{Excitation function of the reaction ${ }^{\text {nat }} \mathrm{Ag}(p, x n){ }^{104} \mathrm{Cd}$}

The product nuclide is expected to be formed directly via the reactions ${ }^{107} \mathrm{Ag}(p, 4 n)$ and ${ }^{109} \mathrm{Ag}(p, 6 n)$ in the silver target of natural isotopic composition. The measured values are shown in Fig. 1 together with the results based on precompound-hybrid model calculations and given in the file MENDL-2P [9]. The peak in the excitation function at around $44 \mathrm{MeV}$ is attributed to the ${ }^{107} \mathrm{Ag}(p, 4 n)$ reaction $(Q=-29.42 \mathrm{MeV})$. The MENDL-2P results give an excitation function that has a maximum at about the same energy as the peak of the experimental cross sections but the 
Table 2. Measured cross sections for the production of ${ }^{103} \mathrm{Ag},{ }^{104 m, g} \mathrm{Ag},{ }^{104 g} \mathrm{Ag},{ }^{104} \mathrm{Cd}$ and ${ }^{105} \mathrm{Cd}$.

\begin{tabular}{|c|c|c|c|c|c|}
\hline \multirow[t]{2}{*}{ Energy (MeV) } & \multicolumn{5}{|c|}{ Cross sections (mb) } \\
\hline & ${ }^{103} \mathrm{Ag}$ & ${ }^{104 m, g} \mathrm{Ag}$ & ${ }^{104 g} \mathrm{Ag}$ & ${ }^{104} \mathrm{Cd}$ & ${ }^{105} \mathrm{Cd}$ \\
\hline $65.2 \pm 0.2$ & $162 \pm 24$ & & & & \\
\hline $63.5 \pm 0.2$ & $166 \pm 23$ & & & & \\
\hline $62.4 \pm 0.2$ & $164 \pm 25$ & & & & \\
\hline $60.7 \pm 0.2$ & $155 \pm 23$ & $143 \pm 22$ & $84 \pm 13$ & $65 \pm 10$ & \\
\hline $59.6 \pm 0.2$ & $154 \pm 23$ & $134 \pm 20$ & $87 \pm 13$ & $56 \pm 9$ & \\
\hline $57.9 \pm 0.3$ & $141 \pm 21$ & $147 \pm 22$ & $102 \pm 16$ & $59 \pm 9$ & \\
\hline $56.7 \pm 0.3$ & $136 \pm 20$ & $145 \pm 23$ & $99 \pm 16$ & $63 \pm 10$ & \\
\hline $54.9 \pm 0.3$ & $117 \pm 19$ & $149 \pm 23$ & $104 \pm 16$ & $69 \pm 11$ & $180 \pm 27$ \\
\hline $53.7 \pm 0.3$ & $97 \pm 16$ & $150 \pm 23$ & $102 \pm 16$ & $80 \pm 12$ & $127 \pm 20$ \\
\hline $52.0 \pm 0.3$ & $75 \pm 12$ & $152 \pm 24$ & $119 \pm 18$ & $95 \pm 13$ & $90 \pm 19$ \\
\hline $49.5 \pm 0.3$ & $46 \pm 7$ & $151 \pm 24$ & $112 \pm 18$ & $108 \pm 16$ & $92 \pm 15$ \\
\hline $46.9 \pm 0.4$ & $20 \pm 3$ & $148 \pm 23$ & $140 \pm 22$ & $118 \pm 18$ & $78 \pm 12$ \\
\hline $44.2 \pm 0.4$ & $6 \pm 1$ & & & $120 \pm 19$ & $78 \pm 15$ \\
\hline $41.5 \pm 0.4$ & & $131 \pm 20$ & $120 \pm 20$ & $91 \pm 15$ & $88 \pm 15$ \\
\hline $38.5 \pm 0.4$ & & $61 \pm 10$ & $53 \pm 9$ & $51 \pm 8$ & $108 \pm 23$ \\
\hline $35.6 \pm 0.5$ & & $15 \pm 3$ & $11 \pm 2$ & $12 \pm 2$ & $170 \pm 26$ \\
\hline $32.4 \pm 0.5$ & & & & & $230 \pm 34$ \\
\hline
\end{tabular}

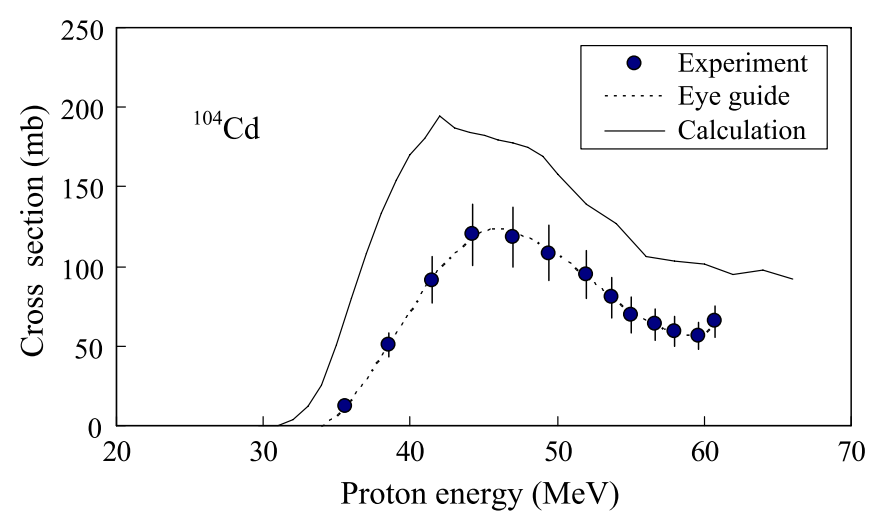

Fig. 1. Excitation function of the ${ }^{\text {nat }} \mathrm{Ag}(p, x)^{104} \mathrm{Cd}$ reaction. The calculation describes the normalized results from the file MENDL-2P [9].

magnitude is much higher. It should be mentioned that the theoretically obtained data were normalized to ${ }^{\text {nat }} \mathrm{Ag}$. The MENDL-2P file gives data for each isotope separately. For comparison with the measured data on ${ }^{\text {nat }} \mathrm{Ag}$, we converted the isotopic data to the elemental data according to the abundances of the contributing target isotopes, and, similar to the experimental data, the calculational curve shows the elemental cross sections. From the overall general form of the MENDL-2P values, an overestimation of the ${ }^{107} \mathrm{Ag}(p, 4 n)$ reaction cross section is obvious. The contribution of the ${ }^{109} \mathrm{Ag}(p, 6 n){ }^{104} \mathrm{Cd}$ process is not evident, its threshold being around $60 \mathrm{MeV}$.

\subsection{Excitation function of the reaction ${ }^{\text {nat }} \operatorname{Ag}(p, x n){ }^{105} \mathrm{Cd}$}

The radionuclide ${ }^{105} \mathrm{Cd}$ is expected to be produced via the ${ }^{107} \mathrm{Ag}(p, 3 n)(Q=-21.59 \mathrm{MeV})$ and ${ }^{109} \mathrm{Ag}(p, 5 n)(Q=$ $-37.45 \mathrm{MeV})$ reactions. The measured results in the energy range of 32 to $55 \mathrm{MeV}$ and the MENDL-2P values are given in Fig. 2. The initial peak at around $32 \mathrm{MeV}$ is attributed to the contribution of the ${ }^{107} \mathrm{Ag}(p, 3 n)$ reaction. The somewhat rising trend from $50 \mathrm{MeV}$ onwards is due to the onset of the ${ }^{109} \mathrm{Ag}(p, 5 n)$ process. A good consistency in shape is found between the experimental and MENDL-2P values, though there appears to be some energy shift in the lower energy region.

\subsection{Excitation function of the reaction ${ }^{\text {nat }} \mathrm{Ag}(p, x)^{103} \mathrm{Ag}$}

The activity of ${ }^{103} \mathrm{Ag}$ in the foils was measured through the $118 \mathrm{keV}$ and $148 \mathrm{keV}$ gamma-lines and about $98 \%$ consistency was found among them. The measurements were done within 47 to $117 \mathrm{~min}$ after EOB. Therefore, ${ }^{103} \mathrm{Cd}$ ( $T_{1 / 2}=7.3 \mathrm{~min}$ ) had fully decayed to ${ }^{103} \mathrm{Ag}$ before measurement. The data for ${ }^{103} \mathrm{Ag}$ thus contain three contributions - direct formation of ${ }^{103 g} \mathrm{Ag}$ via the contributing reactions given in Table 1, total decay of the $15 \mathrm{~s}$ half-life ${ }^{103 \mathrm{~m}} \mathrm{Ag}$ to the ground state, and total decay of the short-lived parent ${ }^{103} \mathrm{Cd}$ $\left(T_{1 / 2}=7.3 \mathrm{~min}\right)$. The measured data are shown in Fig. 3 along with the MENDL-2P calculated values. The theoretical cross section curve also gives a sum of ${ }^{103} \mathrm{Ag}$ formation cross sections, i.e. both directly and via the decay of the ${ }^{103} \mathrm{Cd}$ precursor. The shape of the theoretical curve is similar to the experimental data, though its magnitude is somewhat lower in the low-energy region.

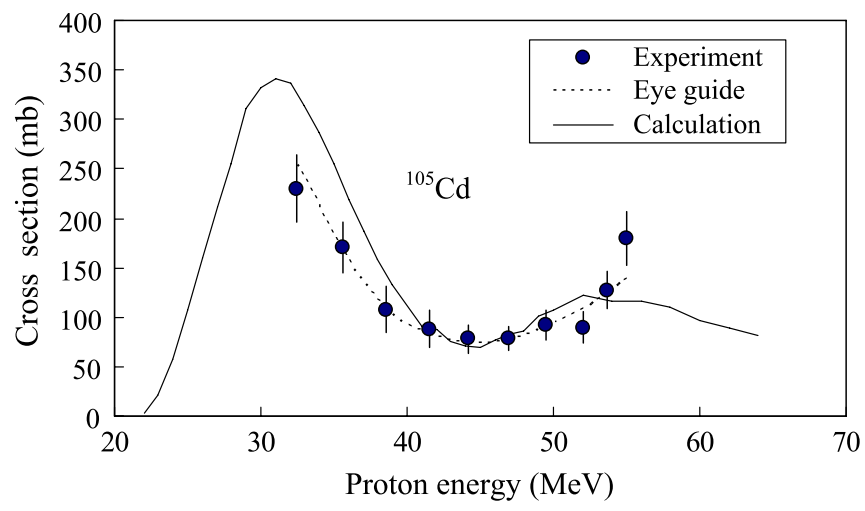

Fig. 2. Excitation function of the ${ }^{\text {nat }} \mathrm{Ag}(p, x)^{105} \mathrm{Cd}$ reaction. The calculation describes the normalized results from the file MENDL-2P [9]. 


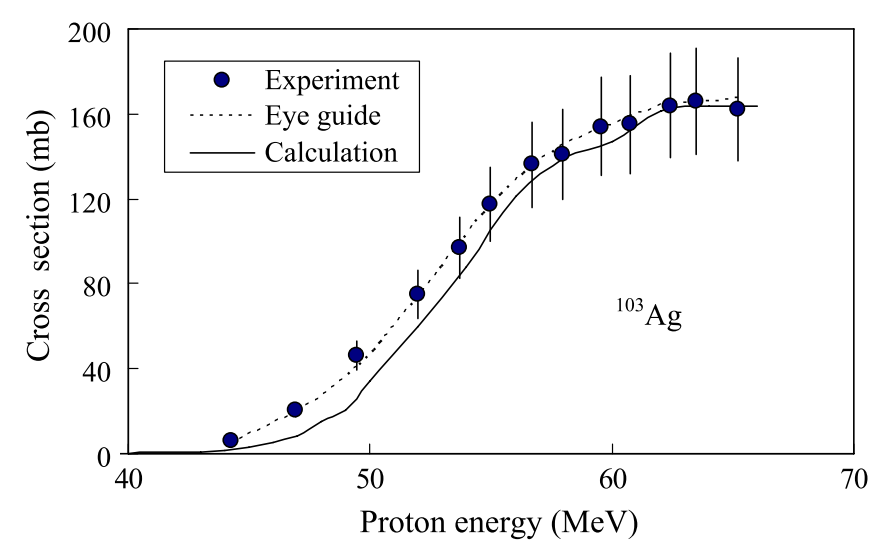

Fig. 3. Excitation function of the ${ }^{\text {nat }} \mathrm{Ag}(p, x)^{103} \mathrm{Ag}$ reaction. The calculation describes the normalized results from the file MENDL-2P [9].

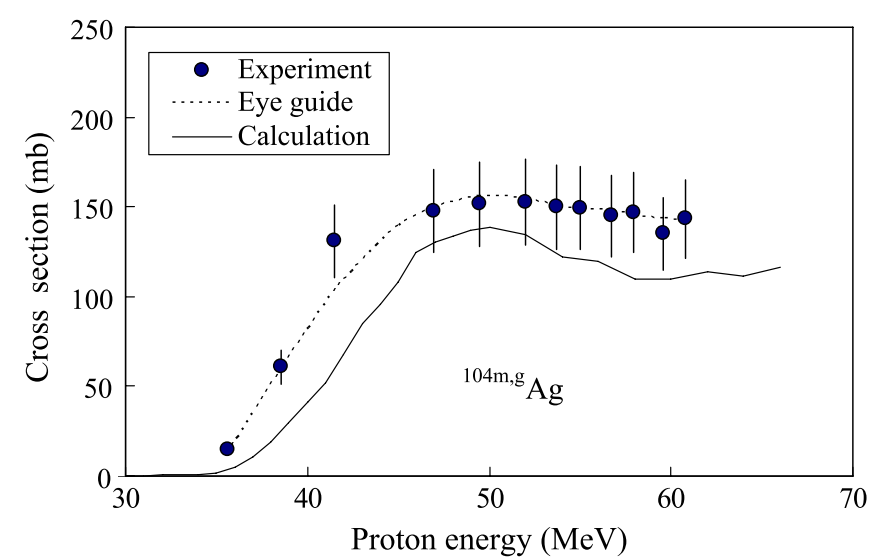

Fig. 4. Excitation function of the ${ }^{\text {nat }} \mathrm{Ag}(p, x)^{104 m, g} \mathrm{Ag}$ reaction. The calculation describes the normalized results from the file MENDL-2P [9].

\subsection{Excitation function of the reaction ${ }^{\text {nat }} \mathrm{Ag}(p, x)^{104 \mathrm{~m}, \mathrm{~g}} \mathrm{Ag}$}

The cumulative cross section for the formation of ${ }^{104} \mathrm{Ag}$ was measured, a part of which is produced via the ${ }^{107} \mathrm{Ag}(p, p 3 n)$ ${ }^{104} \mathrm{Ag}$ and ${ }^{109} \mathrm{Ag}(p, p 5 n){ }^{104} \mathrm{Ag}$ reactions and the rest is due to the decay of ${ }^{104} \mathrm{Cd}\left(T_{1 / 2}=57.7 \mathrm{~min}\right)$ within 47 to $117 \mathrm{~min}$ after end of bombardment (EOB), i.e., the measured values for ${ }^{104} \mathrm{Ag}$ are not fully cumulative. The results are shown in Fig. 4 together with the MENDL-2P calculated values. The model calculations have similar shape to this work, but underestimate the experimental values.

\subsection{Excitation function of the reaction ${ }_{\text {nat }} \mathrm{Ag}(p, x)^{104 \mathrm{~g}} \mathrm{Ag}$}

The radionuclide ${ }^{104} \mathrm{Ag}$ has a ground state (spin/parity $5^{+}$, half-life $1.15 \mathrm{~h}$ ) and an excited isomeric state ${ }^{104 \mathrm{~m}} \mathrm{Ag}$ (spin/parity $2^{+}$, half-life $33.5 \mathrm{~min}$ ). The isomeric state decays $0.07 \%$ by internal transition to the ground state with the emission of a $6.9 \mathrm{keV}$ gamma-line. While ${ }^{104 \mathrm{~g}} \mathrm{Ag}$ has several characteristic gamma-lines, the ${ }^{104 \mathrm{~m}} \mathrm{Ag}$ decays with the emission of gamma-lines that are common to ground state. As also the energy related to the internal transition is very low and is not detectable, both states cannot be individually assessed on spectroscopic basis alone. Due to the differences in half-life and the very limited internal transition

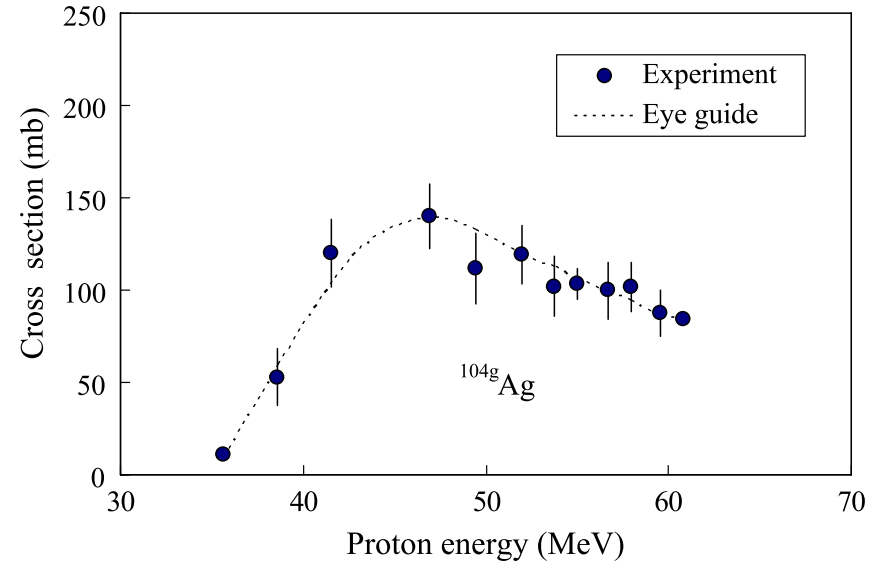

Fig. 5. Excitation function of the ${ }^{\text {nat }} \mathrm{Ag}(p, x)^{104 g} \mathrm{Ag}$ reaction. Since the data refer to one isomeric state, a comparison with results of MENDL$2 \mathrm{P}$ is not given.

probability, the error on the estimation of the total ${ }^{104 \mathrm{~g}} \mathrm{Ag}$ activity could be minimized after a decay time of about three half-lives of ${ }^{104 m} \mathrm{Ag}$. The nuclide ${ }^{104} \mathrm{Cd}$ decays by EC completely to the ground state of ${ }^{104} \mathrm{Ag}$ and contributes strongly to the ground state activity of ${ }^{104} \mathrm{Ag}$. However, ${ }^{104} \mathrm{Cd}$ was independently assessed in this work via its $709 \mathrm{keV} \gamma$-ray (see above). The contribution of ${ }^{104} \mathrm{Cd}$ to the ${ }^{104 \mathrm{~g}} \mathrm{Ag}$ activity could therefore be separated in the present measurement. The cross sections for the production of ${ }^{104 \mathrm{~g}} \mathrm{Ag}$ reported in this work thus describe independent formation cross sections and are shown in Fig. 5. Since they are only partial cross sections, i.e. give the formation of only one isomeric state, a comparison with the MENDL-2P data is not given.

\subsection{Integral yields}

The integral yield of a radionuclide from a nuclear process was deduced using the measured excitation function and the stopping power of nat $\mathrm{Ag}$. It is expressed as $\mathrm{MBq} \mu \mathrm{A}^{-1} \mathrm{~h}^{-1}$, i.e. for an irradiation of $1 \mathrm{~h}$ at a beam current of $1 \mu \mathrm{A}$. The yields of ${ }^{104} \mathrm{Cd},{ }^{105} \mathrm{Cd},{ }^{103} \mathrm{Ag}$ and ${ }^{104 \mathrm{~g}} \mathrm{Ag}$, calculated from the eye-guide curves given in Figs. 1 to 3 and 5, respectively, are shown in Fig. 6. The yields of ${ }^{103} \mathrm{Pd}$ in the interactions of protons with ${ }^{\text {nat }} \mathrm{Ag}$ were estimated separately for its cumulative formation as well as for formation via the decay of the ${ }^{103} \mathrm{Ag}$ precursor. For this purpose we utilized the excitation function for the formation of ${ }^{103} \mathrm{Ag}$ measured in this work (Fig. 3) and the literature data for the cumulative formation of ${ }^{103} \mathrm{Pd}[1,3]$. The results are shown in Fig. 7 for the energy range of 45 to $68 \mathrm{MeV}$. The yield for the formation of ${ }^{103} \mathrm{Pd}$ via the ${ }^{103} \mathrm{Rh}(p$, $n$ ) reaction in the lower energy range [10] is also given in Fig. 7. Obviously, over the energy range $E p=65 \rightarrow$ $44 \mathrm{MeV}$, the cumulative formation yield of ${ }^{103} \mathrm{Pd}$ calculated from the two literature reports $[1,3]$ is in agreement. On the other hand, the yield of ${ }^{103} \mathrm{Pd}$ via the ${ }^{103} \mathrm{Ag}$ precursor decay, calculated from the data measured in this work, amounts to $21 \mathrm{MBq} / \mu \mathrm{Ah}$. Thus about $70 \%$ of ${ }^{103} \mathrm{Pd}$ is formed via the ${ }^{103} \mathrm{Ag}$ precursor route and the rest directly via other competing processes. The result is rather surprising since in the mass region around 100 the most dominating processes are $(p, x n)$ and $(p, p x n)$, which in the case of nat $\mathrm{Ag}$ target would lead to ${ }^{103} \mathrm{Ag}$. The contribu- 


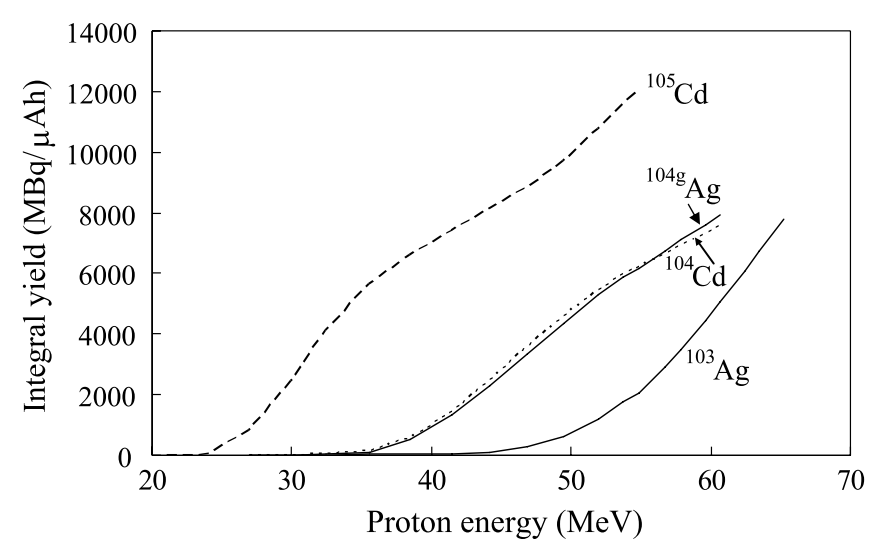

Fig. 6. Integral yields of ${ }^{104} \mathrm{Cd},{ }^{105} \mathrm{Cd},{ }^{103} \mathrm{Ag}$ and ${ }^{1048} \mathrm{Ag}$ from a natural silver target as a function of proton energy.

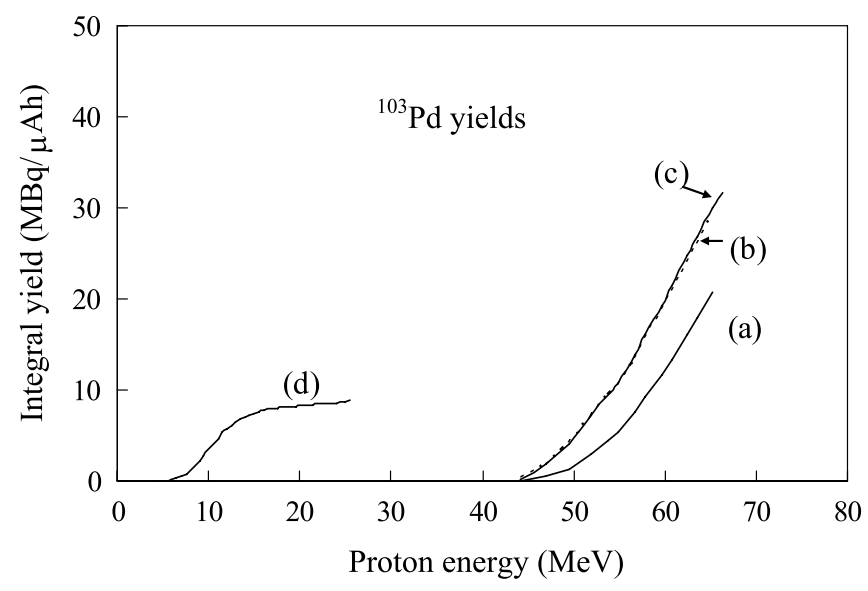

Fig. 7. Integral yield of ${ }^{103} \mathrm{Pd}$ : (a) formed via the ${ }^{\text {nat }} \mathrm{Ag}(p, x)^{103} \mathrm{Ag} \rightarrow$ ${ }^{103} \mathrm{Pd}$ process, (b) total yield deduced from the reported cumulative data of Fassbender et al. [1], (c) total yield deduced from the reported cumulative data of Uddin et al. [3], and (d) formed via the ${ }^{103} \mathrm{Rh}(p, n){ }^{103} \mathrm{Pd}$ reaction (Suda'r et al. [10]).

tions of $(p, \alpha n)$ and $(p, 2 p x n)$ processes on ${ }^{\text {nat }} \mathrm{Ag}$ leading directly to ${ }^{103} \mathrm{Pd}$ are expected to be rather weak. Thus the expected contribution of the ${ }^{103} \mathrm{Ag} \rightarrow{ }^{103} \mathrm{Pd}$ decay process may be around $80 \%-90 \%$. Possibly the uncertainties in the reported data are larger than the estimated values, so that the value of $70 \%$ found in this work may be considered as reasonable.

\section{Comparison of production routes of ${ }^{103} \mathrm{Pd}$}

Six different routes are potentially useful or have already been investigated for the production of ${ }^{103} \mathrm{Pd}$. They are discussed below.

a) ${ }^{102} \mathrm{Pd}(n, \gamma){ }^{103} \mathrm{Pd}$. The abundance of the target nuclide is only $1.02 \%$ and the reaction cross section is not very high. The achievable specific activity is therefore low. The use of an isotopically enriched target and irradiation in a high flux reactor would increase the specific activity. Some attempts are underway in this direction in a few institutes.

b) ${ }^{104} \mathrm{Pd}(\gamma, n){ }^{103} \mathrm{Pd}$. The higher abundance of the target nuclide $(11.14 \%)$ as compared to ${ }^{102} \mathrm{Pd}$ and the use of highenergy bremsstrahlung may lead to high product yield; the specific activity in this case, however, would also not be high. This route is presently under critical consideration in a few laboratories.

c) ${ }^{103} \mathrm{Rh}(p, n){ }^{103} \mathrm{Pd}$. This is the most commonly used method since it leads to no-carrier-added product of very high quality and a small-sized cyclotron is adequate.

d) ${ }^{103} \mathrm{Rh}(d, 2 n){ }^{103} \mathrm{Pd}$. The cross section of this reaction is higher than that of the $(p, n)$ reaction [11]. However, due to the difficulty in obtaining high intensity deuteron beams this reaction has so far not found any application.

e) ${ }^{\text {nat }} \mathrm{Pd}(p, x n){ }^{103} \mathrm{Ag} \rightarrow{ }^{103} \mathrm{Pd}$. The method is rather cumbersome since it would involve periodic separation of ${ }^{103} \mathrm{Ag}$ and therefrom subsequent isolation of ${ }^{103} \mathrm{Pd}$. Furthermore, a $30 \mathrm{MeV}$ proton beam would be needed and the expected ${ }^{103} \mathrm{Pd}$ yield is low.

f) ${ }^{\text {nat }} \operatorname{Ag}(p, x)^{103} \mathrm{Pd}$. The present work has shown that out of the total amount of ${ }^{103} \mathrm{Pd}$ formed (over the energy range $E p=65 \rightarrow 44 \mathrm{MeV}$ ), about $70 \%$ is formed via the ${ }^{103} \mathrm{Ag} \rightarrow{ }^{103} \mathrm{Pd}$ route. The use of this precursor method, on the other hand, has no real advantage. It is preferable to perform a long irradiation and to accumulate ${ }^{103} \mathrm{Pd}$, which could then be separated from the silver target. The long irradiation would not cause any serious contamination of ${ }^{103} \mathrm{Pd}$ since most of the activation products decay to stable isotopes of palladium. The only possible drawback could be the lowering of specific activity of ${ }^{103} \mathrm{Pd}$ due to other stable palladium isotopes formed in long irradiations.

The above discussion leads to the conclusion that for the production of no-carrier-added ${ }^{103} \mathrm{Pd}$ two processes are most suitable, namely ${ }^{103} \mathrm{Rh}(p, n){ }^{103} \mathrm{Pd}$ and ${ }^{\text {nat }} \mathrm{Ag}(p, x){ }^{103} \mathrm{Pd}$. Despite its lower yield, the former reaction is the method of choice because it needs only a low-energy cyclotron $(E p=$ $14 \rightarrow 9 \mathrm{MeV})$. Since such cyclotrons with high beam currents are commercially available, $\mathrm{GBq}$ amounts of ${ }^{103} \mathrm{Pd}$ are easily produced. The ${ }^{\text {nat }} \mathrm{Ag}(\mathrm{p}, x)^{103} \mathrm{Pd}$ process needs higher energies $(E p=68 \rightarrow 44 \mathrm{MeV})$ and the beam intensities available are rather low, so that the batch yield of ${ }^{103} \mathrm{Pd}$ is not high. Nonetheless, this reaction is an interesting alternative route for production of ${ }^{103} \mathrm{Pd}$.

\section{Concluding remarks}

Excitation functions for the formation of a few short-lived radionuclides via the $(p, x n)$ and $(p, p x n)$ reactions on ${ }^{\text {nat }} \mathrm{Ag}$ were measured for the first time from 32 to about $60 \mathrm{MeV}$. Theoretical calculations using the precompoundhybrid model code ALICE-IPPE gave results which are partially consistent with the experimental data. The results are rather surprising since several earlier studies $c f$. [12,13] on such reactions showed good consistency. On the other hand, the present study differs in three ways:

a) the number of emitted nucleons is much higher (up to 7);

b) no parameterization has been done in the calculations, i.e. the results describe a priori calculations;

c) experimental data were obtained using ${ }^{\text {nat }} \mathrm{Ag}$ whereas the theoretical data were obtained by normalizing the isotopic data. 
Experimental data like the ones measured in this work could thus play an important role in improving the models and adjusting input parameters.

As far as the practical application of data is concerned, it could be shown that the intermediate energy proton irradiation of nat $\mathrm{Ag}$ leads to an appreciably higher yield of ${ }^{103} \mathrm{Pd}$ than the commonly used ${ }^{103} \mathrm{Rh}(p, n){ }^{103} \mathrm{Pd}$ reaction. If an intermediate energy cyclotron with a high beam intensity would be available, the ${ }^{\text {nat }} \mathrm{Ag}(p, x){ }^{103} \mathrm{Pd}$ process could thus be quite interesting $c f$. also $[1,3]$.

Acknowledgment. Thanks to Monbukagakusho for a stipend to M. S. Uddin in Japan. The authors thank the cyclotron operation crew and colleagues of CYRIC, Sendai, for their help in performing the irradiations. The authors are highly grateful to Dr. F. Ta'rka'nyi, Institute of Nuclear Research of the Hungarian Academy of Sciences, Debrecen, H-4001, Hungary, for discussions.

\section{References}

1. Fassbender, M., Nortier, F. M., Schroeder, I. W., Van der Walt, T. N.: The production of ${ }^{103} \mathrm{Pd}$ via the ${ }^{\text {nat }} \mathrm{Ag}(p, x){ }^{103} \mathrm{Pd}$ nuclear process. Radiochim. Acta 87, 87 (1999).

2. Hermanne, A., Taka'cs, S., Ta'rka'nyi, F., Belbos, R.: Cross section measurements of proton and deuteron induced formation of ${ }^{103} \mathrm{Ag}$ in natural palladium. Radiochim. Acta 92, 215 (2004).

3. Uddin, M. S., Hagiwara, M., Baba, M., Tarkanyi, F., Ditroi, F.: Experimental studies on excitation functions of the proton-induced activation reactions on silver. Appl. Radiat. Isotopes 62, 533 (2005).

4. Nudat. http://www.nndc.bnl.gov/nudat2/index.jsp.
5. Uddin, M. S., Hagiwara, M., Tarkanyi, F., Ditroi, F., Baba, M.: Experimental studies on the proton-induced activation reactions of molybdenum in the energy range $22-67 \mathrm{MeV}$. Appl. Radiat. Isotopes 60, 911 (2004).

6. Ta'rka'nyi, F., Taka'cs, S., Gul, K., Hermanne, A., Mustafa, M. G., Nortier, M., Oblozinsky, P., Qaim, S. M., Scholten, B., Shubin, Y. N., Youxiang, Z.: Beam monitor reactions, IAEATECDOC-1211 (2001), IAEA, Vienna, Chapter 4. Available from www-nds.iaea.or.at/medical, p. 49.

7. Ziegler, J. F., Biersack, J. P., Littmark, U.: SRIM 2003 Code, The Stopping and Range of Ions in Solids. Pergamon, New York (2003).

8. Torii, A., Uwamino, Y., Nakamura, T.: INS-T-468, Institute for Nuclear Study, University of Tokyo (1987).

9. Shubin, Y. N., Lunev, V. P., Konobeyev, A. Y., Dityuk, A. I.: MENDL-2P Proton reaction data library for nuclear activation (Medium Energy Nuclear Data Library), IAEA-NDS-204 (1998).

10. Suda'r, S., Cserpa'k, F., Qaim, S. M.: Measurements and nuclear model calculations on proton-induced reactions on ${ }^{103} \mathrm{Rh}$ up to $40 \mathrm{MeV}$ : evaluation of the excitation function of the ${ }^{103} \mathrm{Rh}(p, n){ }^{103} \mathrm{Pd}$ reaction relevant to the production of the therapeutic radionuclide ${ }^{103} \mathrm{Pd}$. Appl. Radiat. Isotopes 56, 821 (2002).

11. Hermanne, A., Sonck, M., Taka'cs, S., Ta'rka'nyi, F., Shubin, Yu. N.: Study on alternative production of ${ }^{103} \mathrm{Pd}$ and characterization of contaminants in the deuteron irradiation of ${ }^{103} \mathrm{Rh}$ up to $21 \mathrm{MeV}$. Nucl. Instrum. Methods B 187, 3 (2002).

12. Hohn, A., Nortier, F. M., Scholten, B., Van der Walt, T. N., Coenen, H. H., Qaim, S. M.: Excitation functions of ${ }^{125} \mathrm{Te}(p, x n)-$ reactions from their respective thresholds up to $100 \mathrm{MeV}$ with special reference to the production of ${ }^{124} \mathrm{I}$. Appl. Radiat. Isotopes 55, 149 (2001).

13. Kastleiner, S., Shubin, Y. N., Nortier, F. M., Van der Walt, T. N., Qaim, S. M.: Experimental studies and nuclear model calculations on $(p, x n)$ and $(p, p x n)$ reactions on ${ }^{85} \mathrm{Rb}$ from their thresholds up to $100 \mathrm{MeV}$. Radiochim. Acta 92, 449 (2004). 